\title{
Crystal structure of 2-benzoylpyrene, $\mathrm{C}_{23} \mathrm{H}_{14} \mathrm{O}$
}

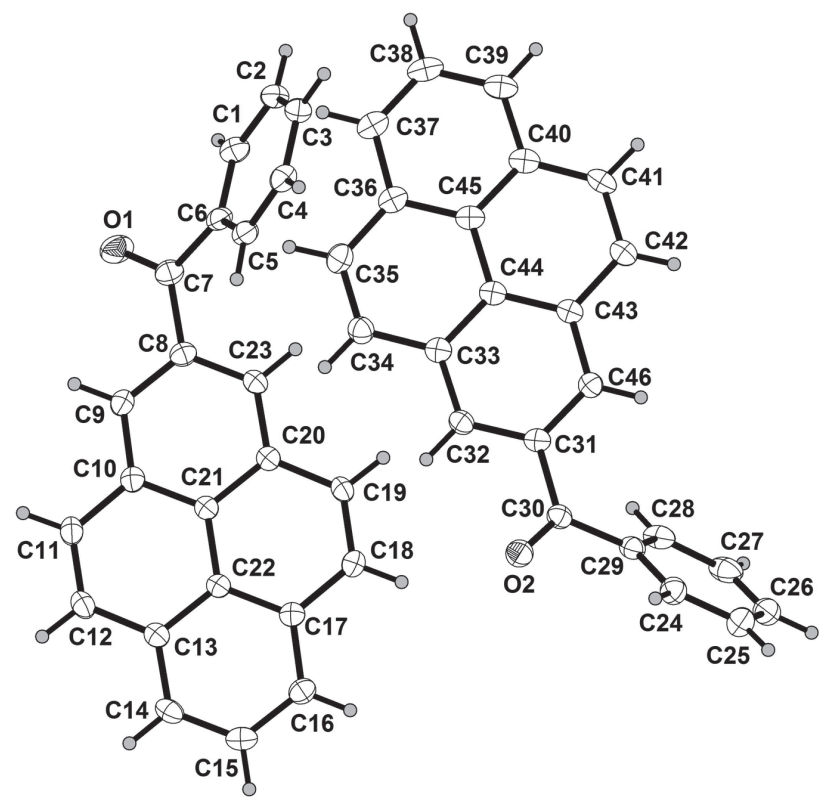

https://doi.org/10.1515/ncrs-2019-0790

Received October 24, 2019; accepted December 20, 2019; available online January 21, 2020

\section{Abstract \\ $\mathrm{C}_{23} \mathrm{H}_{14} \mathrm{O}, \quad$ monoclinic, $P 2_{1} / c \quad$ (no. 14), $\quad a=12.931$ (3) $\AA$, $b=10.486(2) \AA, \quad c=23.004(5) \AA, \quad \beta=104.80(3)^{\circ}$, $V=3015.6(11) \AA^{3}, Z=8, R_{\mathrm{gt}}(F)=0.0524, w R_{\mathrm{ref}}\left(F^{2}\right)=0.1375$, $T=123(2) \mathrm{K}$.}

\section{CCDC no.: 1973248}

The asymmetric unit of the title crystal structure is shown in the figure. Table 1 contains crystallographic data and Table 2 contains the list of the atoms including atomic coordinates and displacement parameters.

\footnotetext{
*Corresponding author: Yun Zhao, School of Chemical Engineering and Technology, China University of Mining and Technology, Xuzhou 221116, Jiangsu Province, P.R. China, e-mail: zhaoyun@cumt.edu.cn. https://orcid.org/0000-0003-27548052

Jing-Yang Li, Bao-Xi Miao and Li-Fang Zhang: School of Chemical Engineering and Technology, China University of Mining and Technology, Xuzhou 221116, Jiangsu Province, P.R. China
}

Table 1: Data collection and handling.

\begin{tabular}{ll}
\hline Crystal: & Yellow block \\
Size: & $0.10 \times 0.10 \times 0.08 \mathrm{~mm}$ \\
Wavelength: & Mo $K \alpha$ radiation $(0.71073 \AA$ A $)$ \\
$\mu:$ & $0.08 \mathrm{~mm}^{-1}$ \\
Diffractometer, scan mode: & Bruker APEX-II, $\varphi$ and $\omega$-scans \\
$\theta_{\max }$, completeness: & $27.5^{\circ},>99 \%$ \\
$N(h k l)_{\text {measured }}, N(h k l)_{\text {unique }}, R_{\text {int }}:$ & $24470,6805,0.042$ \\
Criterion for $I_{\text {obs }}, N(h k l)_{\text {gt }}:$ & $I_{\text {obs }}>2 \sigma\left(I_{\text {obs }}\right), 4937$ \\
$N(\text { param })_{\text {refined }}:$ & 433 \\
Programs: & Bruker programs [1], SHELX [2, 3], \\
& PLATON [4] \\
\hline
\end{tabular}

Table 2: Fractional atomic coordinates and isotropic or equivalent isotropic displacement parameters $\left(\AA^{2}\right)$.

\begin{tabular}{lrrrr}
\hline Atom & $\boldsymbol{x}$ & $\boldsymbol{y}$ & $\boldsymbol{z}$ & $\boldsymbol{U}_{\text {iso }}{ }^{*} \boldsymbol{U}_{\text {eq }}$ \\
\hline O1 & $1.02634(10)$ & $0.63596(12)$ & $0.05932(5)$ & $0.0394(3)$ \\
O2 & $0.39545(9)$ & $0.65809(10)$ & $0.16360(5)$ & $0.0310(3)$ \\
C1 & $0.89505(13)$ & $0.78178(16)$ & $-0.03752(8)$ & $0.0291(4)$ \\
H1 & 0.9443 & 0.8331 & -0.0112 & $0.035^{*}$ \\
C2 & $0.84704(14)$ & $0.82490(17)$ & $-0.09496(8)$ & $0.0314(4)$ \\
H2 & 0.8628 & 0.9058 & -0.1069 & $0.038^{*}$ \\
C3 & $0.77541(13)$ & $0.74734(17)$ & $-0.13462(7)$ & $0.0299(4)$ \\
H3 & 0.7444 & 0.7757 & -0.1735 & $0.036^{*}$ \\
C4 & $0.74977(13)$ & $0.62796(16)$ & $-0.11677(7)$ & $0.0278(4)$ \\
H4 & 0.7021 & 0.5760 & -0.1437 & $0.033^{*}$ \\
C5 & $0.79525(12)$ & $0.58588(16)$ & $-0.05874(7)$ & $0.0252(3)$ \\
H5 & 0.7760 & 0.5070 & -0.0463 & $0.030^{*}$ \\
C6 & $0.86977(12)$ & $0.66146(15)$ & $-0.01898(7)$ & $0.0247(3)$ \\
C7 & $0.93111(13)$ & $0.61109(15)$ & $0.04071(7)$ & $0.0264(4)$ \\
C8 & $0.87602(12)$ & $0.52903(15)$ & $0.07645(7)$ & $0.0233(3)$ \\
C9 & $0.93443(12)$ & $0.43320(15)$ & $0.11275(7)$ & $0.0235(3)$ \\
H9 & 1.0066 & 0.4227 & 0.1146 & $0.028^{*}$ \\
C10 & $0.88560(12)$ & $0.35307(15)$ & $0.14632(7)$ & $0.0221(3)$ \\
C11 & $0.94133(13)$ & $0.24981(15)$ & $0.18197(7)$ & $0.0258(4)$ \\
H11 & 1.0134 & 0.2369 & 0.1841 & $0.031^{*}$ \\
C12 & $0.89121(13)$ & $0.17108(15)$ & $0.21247(7)$ & $0.0260(4)$ \\
H12 & 0.9294 & 0.1047 & 0.2349 & $0.031^{*}$ \\
C13 & $0.78020(12)$ & $0.18766(14)$ & $0.21105(6)$ & $0.0214(3)$ \\
C14 & $0.72657(14)$ & $0.10623(15)$ & $0.24147(7)$ & $0.0260(4)$ \\
H14 & 0.7628 & 0.0375 & 0.2629 & $0.031^{*}$ \\
C15 & $0.61980(14)$ & $0.12638(15)$ & $0.24019(7)$ & $0.0280(4)$ \\
H15 & 0.5853 & 0.0711 & 0.2607 & $0.034^{*}$ \\
C16 & $0.56440(13)$ & $0.22834(15)$ & $0.20850(7)$ & $0.0256(3)$ \\
H16 & 0.4931 & 0.2412 & 0.2082 & $0.031^{*}$ \\
C17 & $0.61464(12)$ & $0.31231(14)$ & $0.17699(7)$ & $0.0213(3)$ \\
C18 & $0.55989(12)$ & $0.41852(14)$ & $0.14357(7)$ & $0.0234(3)$ \\
H18 & 0.4893 & 0.4347 & 0.1438 & $0.028^{*}$ \\
C19 & $0.60890(12)$ & $0.49574(14)$ & $0.11162(7)$ & $0.0227(3)$ \\
H19 & 0.5712 & 0.5637 & 0.0902 & $0.027^{*}$ \\
C20 & $0.71821(12)$ & $0.47474(14)$ & $0.11011(6)$ & $0.0203(3)$
\end{tabular}


Table 2 (continued)

\begin{tabular}{|c|c|c|c|c|}
\hline Atom & $x$ & $y$ & $z$ & $U_{\text {iso }}{ }^{*} / U_{\text {eq }}$ \\
\hline $\mathrm{C} 21$ & $0.77610(12)$ & $0.37342(13)$ & $0.14490(6)$ & $0.0193(3)$ \\
\hline $\mathrm{C} 22$ & $0.72364(12)$ & $0.29148(14)$ & $0.17779(6)$ & $0.0195(3)$ \\
\hline $\mathrm{C} 23$ & $0.76917(12)$ & $0.54962(14)$ & $0.07546(7)$ & $0.0226(3)$ \\
\hline $\mathrm{H} 23$ & 0.7312 & 0.6141 & 0.0514 & $0.027^{\star}$ \\
\hline $\mathrm{C} 24$ & $0.19077(13)$ & $0.75655(16)$ & $0.16691(7)$ & $0.0285(4)$ \\
\hline $\mathrm{H} 24$ & 0.1867 & 0.6809 & 0.1454 & $0.034^{\star}$ \\
\hline $\mathrm{C} 25$ & $0.10214(14)$ & $0.79999(18)$ & $0.18448(8)$ & $0.0358(4)$ \\
\hline $\mathrm{H} 25$ & 0.0384 & 0.7544 & 0.1741 & $0.043^{*}$ \\
\hline C26 & $0.10869(15)$ & $0.91169(17)$ & $0.21756(8)$ & $0.0373(4)$ \\
\hline $\mathrm{H} 26$ & 0.0495 & 0.9407 & 0.2296 & $0.045^{\star}$ \\
\hline $\mathrm{C} 27$ & $0.20314(16)$ & $0.97979(16)$ & $0.23253(8)$ & $0.0360(4)$ \\
\hline $\mathrm{H} 27$ & 0.2075 & 1.0540 & 0.2552 & $0.043^{*}$ \\
\hline $\mathrm{C} 28$ & $0.29164(14)$ & $0.93853(15)$ & $0.21414(7)$ & $0.0294(4)$ \\
\hline $\mathrm{H} 28$ & 0.3545 & 0.9859 & 0.2236 & $0.035^{\star}$ \\
\hline C29 & $0.28599(13)$ & $0.82559(15)$ & $0.18135(7)$ & $0.0235(3)$ \\
\hline C30 & $0.37999(12)$ & $0.77357(14)$ & $0.16249(7)$ & $0.0224(3)$ \\
\hline C31 & $0.45175(12)$ & $0.86237(14)$ & $0.14061(7)$ & $0.0220(3)$ \\
\hline C32 & $0.55802(12)$ & $0.82663(14)$ & $0.14633(7)$ & $0.0227(3)$ \\
\hline H32 & 0.5843 & 0.7526 & 0.1672 & $0.027^{\star}$ \\
\hline C33 & $0.62512(12)$ & $0.90006(14)$ & $0.12123(7)$ & $0.0223(3)$ \\
\hline C34 & $0.73496(13)$ & $0.86572(15)$ & $0.12655(7)$ & $0.0269(4)$ \\
\hline H34 & 0.7639 & 0.7952 & 0.1495 & $0.032^{\star}$ \\
\hline C35 & $0.79679(13)$ & $0.93451(16)$ & $0.09866(7)$ & $0.0295(4)$ \\
\hline H35 & 0.8672 & 0.9096 & 0.1024 & $0.035^{\star}$ \\
\hline C36 & $0.75620(13)$ & $1.04472(15)$ & $0.06350(7)$ & $0.0261(4)$ \\
\hline C37 & $0.81766(14)$ & $1.11643(16)$ & $0.03352(7)$ & $0.0306(4)$ \\
\hline H37 & 0.8878 & 1.0919 & 0.0361 & $0.037^{\star}$ \\
\hline $\mathrm{C} 38$ & $0.77661(14)$ & $1.22294(16)$ & $0.00013(7)$ & $0.0318(4)$ \\
\hline $\mathrm{H} 38$ & 0.8190 & 1.2688 & -0.0196 & $0.038^{\star}$ \\
\hline C39 & $0.67228(14)$ & $1.26176(15)$ & $-0.00403(7)$ & $0.0290(4)$ \\
\hline H39 & 0.6456 & 1.3340 & -0.0263 & $0.035^{*}$ \\
\hline $\mathrm{C} 40$ & $0.60674(13)$ & $1.19341(14)$ & $0.02488(7)$ & $0.0244(3)$ \\
\hline C41 & $0.49800(14)$ & $1.22880(15)$ & $0.02096(7)$ & $0.0260(4)$ \\
\hline H41 & 0.4700 & 1.3013 & -0.0007 & $0.031^{*}$ \\
\hline $\mathrm{C} 42$ & $0.43494(13)$ & $1.15951(15)$ & $0.04796(7)$ & $0.0246(3)$ \\
\hline H42 & 0.3646 & 1.1847 & 0.0442 & 0.030 * \\
\hline C43 & $0.47546(12)$ & $1.04783(14)$ & $0.08230(6)$ & $0.0208(3)$ \\
\hline C44 & $0.58303(12)$ & $1.01110(14)$ & $0.08764(6)$ & $0.0214(3)$ \\
\hline C45 & $0.64898(13)$ & $1.08363(14)$ & $0.05884(7)$ & $0.0228(3)$ \\
\hline C46 & $0.41177(12)$ & $0.97325(14)$ & $0.10963(7)$ & $0.0225(3)$ \\
\hline H46 & 0.3417 & 0.9980 & 0.1071 & $0.027^{\star}$ \\
\hline
\end{tabular}

\section{Source of material}

The title compound 2-benzoylpyrene was obtained by two steps using 4,5,9,10-tetrahydrogenpyrene as the starting materials. The educt 4,5,9,10-tetrahydrogenpyrene was prepared according to the previous literature [5]. The whole synthetic procedures were refered to the method reported recently by Zhang et al. [6]. The detailed synthetic processes are described as following. 4,5,9,10-tetrahydrogenpyrene $(7 \mathrm{mmol})$ was dissolved in carbon disulfide $(100 \mathrm{~mL})$ and then anhydrous aluminum chloride ( $14 \mathrm{mmol})$ was added under nitrogen atmosphere. The mixture was kept below $0{ }^{\circ} \mathrm{C}$ and stirred for $30 \mathrm{~min}$. Then it was added dropwise into a solution of benzoyl chloride $(7.4 \mathrm{mmol})$ in carbon disulfide $(20 \mathrm{~mL})$, and the mixture was stirred at room temperature for $10 \mathrm{~h}$. After the reaction completed, the mixture was poured into $150 \mathrm{~mL}$ ice water and stirred overnight. The mixture was extracted with dichloromethane three times and the collected organic layer was combined, washed with brine twice and dried over anhydrous magnesium sulfate. The crude product was condensed and purified on a silica-gel column using a mixture of dichloromethane and hexane as eluent, yielding the intermediate 2-benzoyl-4,5,9,10-tetrahydropyrene as a yellow needle-like crystal (Yield: 87\%). ${ }^{1} \mathbf{H}$ NMR $(400 \mathrm{MHz}$, $\left.\mathrm{CDCl}_{3}\right) \delta$ 7.90-7.82 (m, 2H), $7.62(\mathrm{dd}, J=10.5,4.3 \mathrm{~Hz}, 1 \mathrm{H}), 7.54$ $(\mathrm{dd}, J=15.2,7.4 \mathrm{~Hz}, 4 \mathrm{H}), 7.22(\mathrm{dd}, J=8.2,6.6 \mathrm{~Hz}, 1 \mathrm{H}), 7.14(\mathrm{~d}$, $J=7.4 \mathrm{~Hz}, 2 \mathrm{H}), 2.96(\mathrm{~s}, 8 \mathrm{H})$. MS: $\left(\mathrm{C}_{23} \mathrm{H}_{18} \mathrm{O}\right) \mathrm{m} / \mathrm{z} 310\left(\mathrm{M}^{+}, 100\right)$, 233(58), 202(30), 105(32).

The preparative method of the title compound as follows. A solution of 2-benzoyl-4,5,9,10-tetrahydropyrene (5 mmol) and DDQ (2,3-dichloro-5,6-dicyano-1,4-benzochinone, $11 \mathrm{mmol})$ in dry toluene $(50 \mathrm{~mL})$ were heated at reflux under nitrogen atmosphere for $24 \mathrm{~h}$. The mixture was cooled to room temperature and filtered. The filtrate was washed with 5\% aqueous sodium hydroxide and water and dried over anhydrous magnesium sulfate. The crude product was purified on a silica-gel column using a mixture of dichloromethane and hexane as eluent, yielding light yellow block-like crystals (Yield: 73\%). A suitable block single crystal of the compound for X-ray crystallography was obtained by the slow evaporation of a mixture of dichloromethane/hexane at room temperature. ${ }^{1} \mathbf{H}$ NMR $\left(400 \mathrm{MHz}, \mathrm{CDCl}_{3}\right) \delta 8.62(\mathrm{~s}, 2 \mathrm{H}), 8.25$ (d, $J=7.7 \mathrm{~Hz}, 2 \mathrm{H}), 8.15$ (s, 4H), $8.10(\mathrm{t}, J=7.6 \mathrm{~Hz}, 1 \mathrm{H}), 8.01-$ $7.94(\mathrm{~m}, 2 \mathrm{H}), 7.73 \mathrm{C} 7.65(\mathrm{~m}, 1 \mathrm{H}), 7.59(\mathrm{t}, J=7.6 \mathrm{~Hz}, 2 \mathrm{H}) . \mathbf{M S}$ : $\left(\mathrm{C}_{23} \mathrm{H}_{14} \mathrm{O}\right) \mathrm{m} / \mathrm{z}$ 306( $\left.\mathrm{M}^{+}, 100\right)$, 229(25), 201(60), 105(20), 77(28).

\section{Experimental details}

All $\mathrm{H}$ atoms were introduced using the HFIX commond in the SHELXL program [3], with the value of $0.93 \AA$ A for $\mathrm{C}-\mathrm{H}$ bonds distances. All $\mathrm{H}$ atoms were allowed for as riding atoms with $U_{\text {iso }}(\mathrm{H})=1.2 U_{\text {eq }}(\mathrm{C})$ for all hydrogen atoms. The structure was checked using PLATON [4].

\section{Comment}

Organic optoelectronic materials such as organic light emitting diodes (OLEDs), organic photovoltaic cells (OPV), organic field-effect transistors (OFETs), fluorescent probe, etc. [7]. have aroused much attentions in several fields. Up to date, there are several tens of important functional precursors for the design, synthesis of interesting new organic optoelectronic materials [8]. As one of the well-known starting functional material, new pyrene-based organic functional compounds have been paid everlasting attentions due to 
not only their excellent photophysical properties, but also theirs precursor pyrene easy obtained from coal tar as the huge side product of coal coking. For example, the pyrenebased derivatives OLED has been wide application and broad prospects, because some pyrene-based derivatives are easier to make thinner, lighter, flexible and large-area sheets $[9,10]$. In addition, pyrene-based derivatives also have been widely employed in fluorescent probes with low detection limit and high sensitivity characteristics due to pyrene-based fluorescent probes usually exhibit high solution fluorescence quantum yield and large Stokes shift [11, 12]. But most of the reported pyrene-based derivatives are 1-monosubstituted compounds and 1,3,6,8-tetrasubstituted compounds because 1-, 3-, 6-, 8-positions are commonly active sites of pyrene for nucleophilic substitution reaction. The research on inactive sites such as 2-, 7-position of pyrene recently arouse the interest of scientists [13], which can bring new pyrene-based functional materials with interesting optoelectronic properties. It is very hard to directly obtain 2-, 7-position substituted and pyrene-based derivatives from pyrene, therefore, the 2-substituted and 2,7-disubstituted pyrene-based derivatives are still very limited. Zhang et al. $[6,10]$ have reported the synthesis and crystal structure of one benzoylpyrene with 4-methylbenzoyl group at the 2-position of pyrene via three steps using pyrene as the starting material.

The single crystal X-ray diffraction analysis results are consistent with expectation. There are two independent 2benzoylpyrene molecules in the crystal structure. The crystal structure indicates that the benzoyl group is bonded to the 2position of the pyrene precursor. The functional group $\mathrm{C}-\mathrm{O}$ bond length is 1.2241(19) $\AA$ for C7-O1 and 1.2265(18) $\AA$ for C30-O2 in the two 2-benzoylpyrene molecules, respectively, which conforms to the typical characteristics of the carbonyl $\mathrm{C}-\mathrm{O}$ double bond. The bond angles around the carbonyl group in the two independent 2-benzoylpyrene molecules are $119.73(15)^{\circ}$ for C6-C7-O1 and $119.65(14)^{\circ}$ for O2-C30-C29. All the sixteen carbon atoms of pyrene moiety are located on a nearly strict plane with the largest derivation of $0.073(2) \AA$ for C8 and 0.063(2) A for C31 from the mean plane. The dihedral angel between the pyrene ring and the phenyl moieties are $65.43(15)^{\circ}$ and $65.51(15)^{\circ}$ in the two molecules, respectively. All molecular geometric parameters of both crystallographically independent are in the expected ranges [14]. There are many interactions in the crystal of the title compound. Firstly, there exist strong $\pi-\pi$ interactions between the neighboring pyrene rings with the shortest $\mathrm{C}-\mathrm{C}$ distance of $3.382 \AA$, forming dimeric supramolecular substructures. Then, these dimeric substructures are linked together by $\mathrm{C}-\mathrm{H}$... O hydrogen bonds, giving a one-dimensional zizaglike supramolecular structure. Finally, a three-dimensional network supramolecular structure is obtained based on the above one-dimensional zizag-like supramolecular structures linked by $\mathrm{C}-\mathrm{H}-\pi$ interactions from the adjacent pyrene rings and benzene rings.

Acknowledgements: This work was supported by Science and Technology Project of Xuzhou (No. KC19007) and the Open Sharing Fund for the Large-scale Instruments and Equipments of CUMT.

\section{References}

1. Bruker: APEX3, SAINT-Plus, XPREP. Bruker AXS Inc., Madison, WI, USA (2016).

2. Sheldrick, G. M.: SHELXT - Integrated space-group and crystalstructure determination. Acta Crystallogr. A71 (2015) 3-8.

3. Sheldrick, G. M.: Crystal structure refinement with SHELXL. Acta Crystallogr. C71 (2015) 3-8.

4. Spek, A. L.: Single-crystal structure validation with the program PLATON. J. Appl. Crystallogr. 36 (2003) 7-13.

5. Tintel, C.; Rietmeyer, F. J.; Cornelisse, J.: Photosubstitution and photoreduction of pyrene and 1-halopyrenes. Rec. Trav. Chim. Pays Bas 102 (1983) 224-228.

6. Zhang, R.; Han, F. F.; Zhang, L. F.: Crystal structure of 2-(4methylbenzoyl)pyrene, $\mathrm{C}_{24} \mathrm{H}_{16}$ O. Z. Kristallogr. NCS 231 (2016) 855-857.

7. Sun, H.; Tang, X. X.; Miao, B. X.; Yang, Y.; Ni, Z. H.: A new AIE and TICT-active tetraphenylethene-based thiazole compound: Synthesis, structure, photophysical properties and application for water detection in organic solvents. Sensor Actuat. B-Chem. 267 (2018) 448-456.

8. Sun, H.; Sun, S. S.; Han, F. F.; Ni, Z. H.; Zhang, R.; Li, M. D.: A new tetraphenylethene-based Schiff base: two crystalline polymorphs exhibiting totally different photochromic and fluorescence properties. J. Mater. Chem. C 7 (2019) 7053-7060.

9. Figueira-Duarte, T. M.; Müllen, K.: Pyrene-based materials for organic electronics. Chem. Rev. 111 (2011) 7260-7314.

10. Zhang, R.; Zhao, Y.; Zhang, T. F.; Xu, L.; Ni, Z. H.: A series of short axially symmetrically $1,3,6,8$-tetrasubstituted pyrenebased green and blue emitters with 4-tert-butylphenyl and arylamine attachments. Dyes Pigm. 130 (2016) 106-115.

11. Tang, X. X.; Sun, H.; Nie, J.; Han, X. E.; Zhao, Y.; Zhang, R.; Ni, Z. H.: An o-hydroxyl aldehyde structure based naphthalimide derivative: Reversible photochromic properties and its application in $\mathrm{ClO}^{-}$detection in living cells. Spectrochim. Acta A 219 (2019) 154-163.

12. Nie, J.; Liu, Y.; Niu, J.; Ni, Z. H.; Lin, W. Y.: A new pyrene-based fluorescent probe with large Stokes shift for detecting hydrogen peroxide in aqueous solution and living cells. J. Photoch. Photobio. A 348 (2017) 1-7.

13. Ji, L.; Edkins, R. M.; Lorbach, A.; Krummenacher, I.; Brückner, C.; Eichhorn, A.; Braunschweig, H.; Engels, B.; Low, P. J.; Marder, T. B.: Electron delocalization in reduced forms of 2$\left(\mathrm{BMes}_{2}\right)$ pyrene and 2,7-bis(BMes $\left.{ }_{2}\right)$ pyrene. J. Am. Chem. Soc. 137 (2015) 6750-6753.

14. Xu, Y.-H.; Miao, B.-X.; Zhang, R.: Crystal structure of 2-acetyl pyrene, $\mathrm{C}_{18} \mathrm{H}_{12}$ O. Z. Kristallogr. NCS 234 (2019) 369-371. 